Review

\title{
Development of services for substance use problems: need for a system-based approach
}

Thomas F. Babor ${ }^{1}$

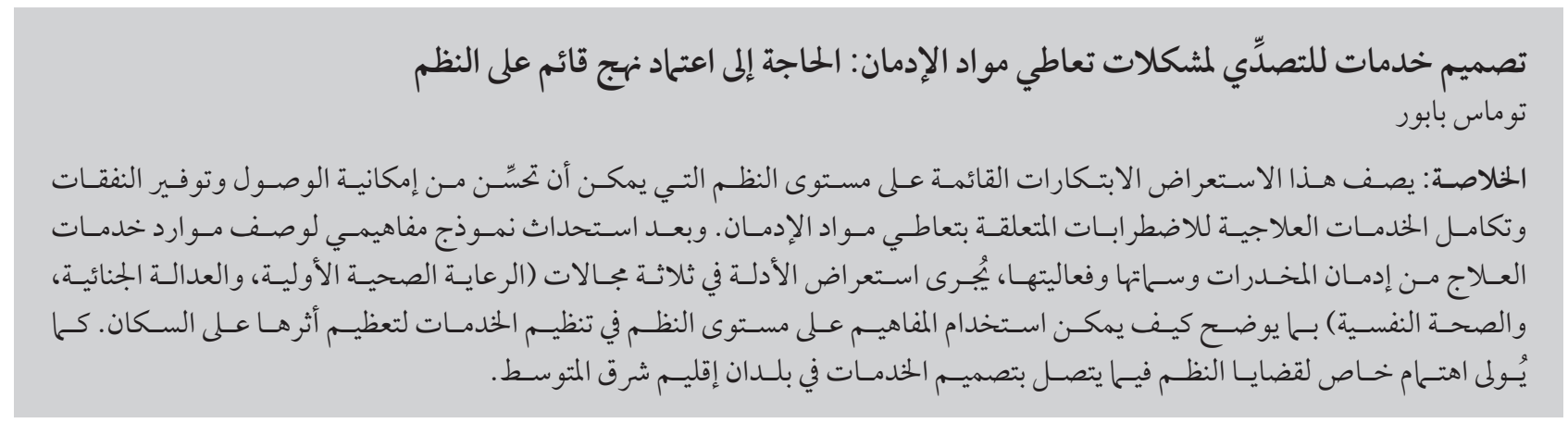

ABSTRACT This review describes systems-level innovations that may enhance accessibility, economy and integration of treatment services for substance-related disorders. After introducing a conceptual model to describe the resources, qualities and effectiveness of drug treatment services, evidence is reviewed in three areas (primary care, criminal justice, and mental health) that illustrate how systems-level concepts can be used to organize services to maximize their population impact. Special attention is given to systems issues in relation to the development of services in countries of the Eastern Mediterranean Region.

Développement des services de prise en charge des problèmes liés à l'utilisation de substances : nécessité d'une approche systémique

RÉSUMÉ La présente étude décrit les innovations systémiques qui pourraient améliorer l'accessibilité, l'économie et l'intégration de services de traitement des troubles liés à la consommation de substances. Après l'introduction d'un modèle conceptuel visant à décrire les ressources, les qualités et l'efficacité des services de traitement de la toxicomanie, les données factuelles sont examinées dans trois domaines (soins primaires, droit pénal, et santé mentale) qui illustrent la façon dont les concepts systémiques peuvent être utilisés pour organiser des services de façon à maximiser l'impact sur la population. Une attention particulière est accordée aux questions systémiques liées au développement de services dans les pays dela Région de la Méditerranée orientale. 


\section{Introduction}

Countries of the Eastern Mediterranean region have both a religious prohibition on alcohol consumption and social discouragement of drinking (1). Nevertheless, there are historical, cultural and religious differences among countries that may affect the meaning of addiction and the societal response to it in terms of treatment interventions. In Saudi Arabia and Kuwait, the possession, sale or consumption of alcohol (regardless of the person's faith) is strictly forbidden. In the United Arab Emirates, the possession, sale or consumption of alcohol by Muslims is illegal but alcohol consumption is offcially permissible for non-Muslims. The use of opioids is strictly prohibited in all countries of the region and penalties for possession and use are severe. To avert a prison sentence, dependent individuals in many countries of the region can present themselves for treatment.

Not only are alcohol and other substances forbidden in Islam, addictive behaviour is socially stigmatized. This may affect the accuracy of epidemiological surveys as well as screening and diagnostic procedures. Nevertheless, there is evidence suggesting that Arab/ Muslim communities in many countries have experienced both endemic and epidemic drug problems $(1,2)$. The condemnation of alcohol and drug use by Islam, the law and the culture within these societies provides an important contextual feature within which treatment programmes must operate; particularly in terms of the effects of stigma and stigmatizing attitudes and the role of the family in prevention and recovery.

The evaluation of treatment effectiveness for patients with substance use disorders is typically based on studies that compare outcomes associated with a particular therapeutic intervention, such as opioid substitution treatment, drug counselling or psychosocial therapy, with an untreated control group or a group exposed to a standard intervention. This is an important way to evaluate treatment, but programme administrators and policy-makers must also consider the cumulative and additive impact of an entire range of treatment services; sometimes referred to as the treatment network or system of services (3). The system approach addresses the question: to what extent does a network of services as a whole affect the incidence and prevalence of substance use disorders at the level of the community or nation? Ideally, a treatment system should be designed to operate as a coordinated and integrated set of services in order to meet the needs of populations as well as individuals.

Research and theory in the area of drug treatment systems is derived mainly from high-income countries, but recently, attention has been devoted to system issues as they affect low- and middle-income countries (where system issues are relevant to the planning and expansion of services; particularly in response to epidemics of substance use (3). After introducing a conceptual model to describe the resources, qualities and effectiveness of drug treatment services, evidence is reviewed in three areas (primary care, criminal justice and mental health) that illustrate how systems-level concepts can be used to organize services to maximize their population impact. In this article, special attention is given to systems issues in relation to the development of services in countries of the Eastern Mediterranean Region, which has unique features that support the need for treatment systems that are tailored to the needs of different populations.

\section{A Treatment Systems Conceptual Model}

The term system refers to coherence, integration and organization. In most countries, services vary in the extent to which their components are integrated, mutually supportive and meet the needs of their target populations. Services for substance use disorders are often fragmented and unevenly distributed; in part because they tend to be financed and managed by multiple agencies. This situation is complicated by the fact that services tend to be distributed across different geographic areas and branches of government $(3,4)$.

Conceptualizing treatment services for drug users as a system raises a set of questions that are not generally considered when specific types of services are evaluated merely in terms of their effectiveness with individual drug users. For example, given the limited amount of financial resources devoted to drug treatment, are there ways of designing service systems to minimize cost while maximizing the public health impact? How should a system balance the need to provide high-intensity services for the most severely impaired drug users with the desire to make effective, but less-intensive services (e.g., outpatient treatment) accessible to those whose drug problems are less serious? In addition to the appropriate mix of services, how can services be made more accessible, efficient, economical and effective by applying systems concepts?

Figure 1 presents a conceptual model for describing a service system and its impact. According to this model (3), the policies of a service system affect its structural resources and system qualities, which in turn determine the effectiveness of a collection of services and their impact on population rates of substance-related problems, including drug overdoses, substance-related disease (e.g., hepatitis and HIV infection), criminal activities and psychiatric disorders.

System policies are regulations, laws and financing mechanisms that affect the type, amount and organization of services. According to a survey conducted by the World Health Organization (WHO) (2), two thirds of the United Nations (UN) member states report having a government unit responsible 


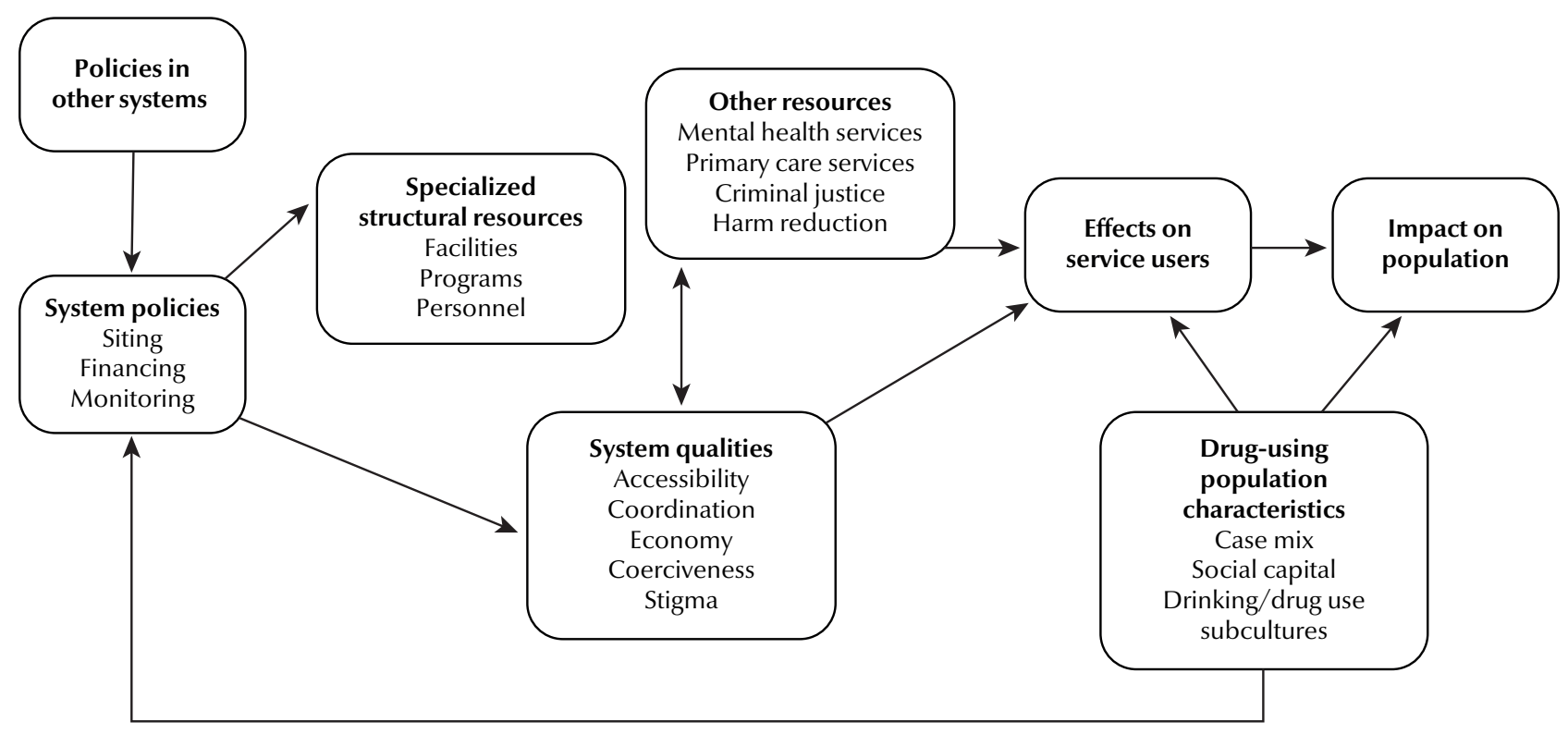

Adapted from Babor et al., 2010

Figure 1. Conceptual model of population impact of service systems

for alcohol and drug treatment services. Nevertheless, only $45.8 \%$ of these countries have an annual budget appropriation for treatment programmes. In many countries, support for drug treatment is combined with funding allocations for mental health services (2). In the Eastern Mediterranean Region, less than half of the countries (42.8\%) have a budget allocation for drug services, and most of these services are provided through mental health budgets. Most countries use tax revenues, user fees and private insurance to pay for alcohol and drug services. Tax funding is more important in high-income countries, whereas out of pocket financing is more common in the poorer countries (2). Out-of-pocket payments seem to play a major role in funding services in the Eastern Mediterranean, with one third of the treatment financed in this way through private clinics and practitioners.

As suggested in the figure, financing and other government policies have a direct effect on the structural resources in the system. These resources include the types of facilities (e.g., hospitals, clinics and hotlines), the programmes delivered in those facilities (e.g., detoxification, rehabilitation, vocational training and psychotherapy), and the personnel in those programmes (e.g., certified counsellors, social workers, psychiatrists and recovering persons). Mental health services, primary care networks, and harm reduction programmes may also constitute resources for the treatment system, to the extent that there are formal or informal linkages with specialized substance abuse services.

In contrast to the structural resources, system qualities are less-tangible parts of the system that are nevertheless important to the overall functioning of a service network. The key qualities of a treatment system are accessibility, coordination, economy, coerciveness and stigma (3). Accessibility refers to how easy or difficult it is to enter a particular service. Coordination refers to whether services are provided in a concerted rather than haphazard fashion, and whether different programmes in the system work synergistically rather than independently or even competitively. The term economy refers to whether the services make efficient use of resources and are cost-effective. Coercion refers to the pressure placed on drug users to seek treatment services. It is most prevalent in the criminal justice system but is often present in more subtle ways (e.g., family pressure) in other types of service. Coerciveness can increase demand for services, but it can also stigmatize the people who use them.

The conceptual model posits that structural resources and system qualities, along with the characteristics of drug using population, are responsible for two important outcomes. The first is the effectiveness of the system in terms of reduced substance use and improved health and social outcomes for clients who use the system. The second is the impact on population health, including overdose deaths, incidence of bloodborne infectious disease, public safety (e.g., amount of property crime), and social welfare (e.g., child abuse rates).

Despite a pervasive assumption that treatment services reduce the burden of disease attributable to drug abuse, there has been virtually no research on this question. Several case studies have suggested that the impact can be significant 
when a new component is added to an existing system. For example, the introduction of large-scale opioid substitution treatment (OST) services in France in the 1990s was associated with a decrease in heroin arrests (5) and drug-related mortality and AIDS cases. Similar reductions in crime occurred in Switzerland following the expansion of opioid substitution treatment. In both countries the heroin market may have been significantly disrupted because a large number of heavy users, many of whom were also heroin sellers, were removed from the drug market (6).

The population impact of alcohol services, particularly Alcoholics Anonymous groups and professionally provided treatment, has been studied in several countries. Smart and Mann (7) found that: 1) increases in Alcoholics Anonymous membership and amount of professionally provided services in the United States of America (USA) and Canada were associated with decreased rates of alcohol problems; and 2) such changes may be large enough to have a considerable impact on hospital admissions and death from liver cirrhosis. Although drug and alcohol treatment and social services can reduce drug-related crime, infectious disease, overdoses, the quantity of drugs consumed and alcohol-related disease, they are unlikely to eliminate a nation's drug or alcohol problems.

\section{Systems-level innovations that may enhance accessibility, economy and integration}

According to the conceptual model, the functioning of the system can be improved by the delivery of substancespecific services as well as the coordination of specialized services with primary health care, criminal justice and mental health services. These kinds of systemslevel innovations have been shown to enhance the accessibility, economy and integration of drug treatment services (8), and they are described here in terms of new care models, early identification programmes, and drug treatment in criminal justice and psychiatric settings.

\section{Care models}

As treatment services became more specialized, new models have been developed to describe how they relate to the different types of population needs. These concepts include the continuumof-care model and the chronic-care model.

The continuum-of-care model refers to the way service users pass through the mix of treatment options available to them (9). In an ideal system, the services are accessed sequentially, beginning with diagnostic assessment, which is then used to assign patients to particular settings according to the acuity, severity and complexity of the diagnosed disorder and the availability of appropriate services. One example of the continuum-of-care model is the stepped-care approach in which patients are assigned initially to the leastintensive level of care. If they do not respond at this level, they are stepped up to a more intensive level.

The chronic-care model addresses the most persistent and serious cases of substance dependence; especially those characterized by co-occurring medical and psychiatric disorders. The model works by coordinating specialized services over time, under the assumption that once substance dependence has developed, there is a need for continuing care and management, as is done with chronic conditions like diabetes and hypertension. Rush (9) has defined a series of tiers that constitute the most important elements of a continuum of services for chronic substance users. They include health promotion, early intervention, crisis management, as well as residential programmes, outpatient counselling, and pharmacotherapy. The highest tier includes specialized care functions for individuals with complex problems, such as inpatient withdrawal management, forensic services and long-term psychiatric care.

\section{Early identification in primary health care}

A public health approach that has attracted the interest of policy-makers and health authorities in many parts of the world is systematic screening for substance use in healthcare and social service settings, followed by brief intervention (for at risk substance users) or referral to treatment (for those who are likely to be drug dependent). This form of early identification is accomplished through the use of self-report questionnaires such as the Alcohol, Smoking and Substance Involvement Screening Test (ASSIST), developed by WHO to improve early detection in primary healthcare settings, as well as schools and emergency departments (10).

Screening is typically followed by a brief intervention, which refers to any time-limited effort (e.g., 1 or 2 conversations or meetings) to provide information or advice, increase motivation to avoid substance use, or to teach behaviour change skills that will reduce substance use as well as the risk of negative consequences. The largest brief intervention study of drug users (11) was conducted by WHO in primary healthcare settings in Australia, Brazil, India and the USA. Drug users scoring within the moderate-risk range on the ASSIST screening test for cannabis, cocaine, amphetamine-type stimulants, or opioids were assigned to either a wait-list control group or an intervention condition where they received brief motivational counselling for the drug receiving the highest risk score. Compared with control participants, those receiving the brief intervention reported significantly reduced drug involvement 3 months later.

In a meta-analytical review of 21 studies of motivational interviewing interventions for adolescent substance 
use behaviour change, Jensen et al. (12) found small but statistically significant effect sizes at follow-up, suggesting that motivational interviewing interventions for adolescent substance use retain their effect over time. Motivational interviewing interventions were effective across a variety of substance use behaviours, session lengths, clinician education levels and setting.

In addition to early identification of at-risk substance users, screening programmes typically identify a smaller proportion of persons with substance dependence. Rapp et al. (13) compared the linkage effect of 2 interventions - 5 sessions of strengths-based case management or 1 session of motivational interviewing - with the referral standard of care at a centralized intake unit in the USA. Strengths-based case management was better than 1 session of motivational interviewing, although both improved linkage with treatment compared to standard care. This research suggests that the routine or opportunistic use of drug screening in primary care and other healthcare settings may improve not only the early identification of substance use disorders, but also the referral of more serious cases to appropriate treatment interventions.

\section{Drug treatment in association with the criminal justice system}

Drug treatment is increasingly being provided as an adjunct to the criminal justice system. It is also used in some countries as an alternative to incarceration. Research suggests that immediate but modest sanctions for positive drug tests produce substantial reductions in drug use and offending among individuals who are under criminal justice supervision. This kind of coerced or mandated abstinence is typically required of offenders on community release, who are drug-tested at least weekly with immediate re-incarceration for a missed or drug-positive test. Mandated abstinence programmes for drug and drink-driving offenders on community release (14) and programmes for addicted physicians (15) have been found to be effective.

Another system innovation is the drug treatment court, which combines drug testing and criminal sanctions with mandatory treatment. Drug courts now operate in all 50 states in the USA and other countries have adopted these programmes as well (16). Drug courts can reduce crime and promote treatment participation $(17,18)$. Evaluations of adult drug treatment courts (19) have found an average drop in recidivism from $50 \%$ to $38 \%$. Rossman et al. (20) found that the drug court programme practices in the USA, such as judicial status hearings, judicial praise, case management, substance abuse treatment and discretionary use of the extent of punishment (in case of noncompliance) were all related to reductions in crime and substance use.

Another area in which criminal justice and drug treatment collaborate in the interests of public health is prison treatment programmes. Research suggests that drug treatment in prisons and after release helps prisoners remain abstinent, prevents recidivism, and facilitates continued employment, especially if a therapeutic community treatment model is used $(21,22)$. Opioid substitution therapy in particular is an effective approach in the prison setting (23).

Nevertheless, there are ethical concerns in some countries about the extent to which legal coercion is being exercised appropriately. Even modest levels of coercion raise ethical questions (24). Some ethicists (25) argue that treatment for drug dependence cannot be administered to an unwilling patient. Others (26) suggest that persons with drug dependence cannot provide informed consent to treatment because they are not autonomous agents. Given the human rights and ethical issues raised by compulsory treatment centres, $12 \mathrm{UN}$ entities including $\mathrm{WHO}$ issued a public request for Member States to close compulsory drug detention and rehabilitation centres and implement voluntary health and social services in the community $(27,28)$.

\section{Treatment in psychiatric settings}

The co-occurrence of substance use disorders and other psychiatric disorders, especially affective and personality disorders, is common among both adults and adolescents. Untreated or poorly treated co-occurring disorders may result in poorer physical health, decreased social functioning and increased risk of being homeless or incarcerated $(29,30)$.

Minkoff (31) has developed a set of principles for the treatment of co-occurring disorders that focus on treatment engagement and case management. This model recommends matching services to the severity of each co-occurring disorder, taking into account diagnosis, treatment phase, and levels of motivation and disability. Within psychiatric settings, Miller and Carroll (32) recommend universal screening for the full range of substance-related problems, followed by brief motivational counselling as a first-line intervention. The general orientation of these models is to reduce the separation between mental health and addiction services by means of programme-level modifications, alterations in clinical practice guidelines, the use of integrated screening tools, and clinician training initiatives (33).

To the extent that the existing literature suggests that continuity of care, a period of abstinence from substance use, and coordination of mental health services are beneficial to persons with co-occurring disorders, the application of systems concepts should result in better outcomes for this population (8). In addition, it is likely that coordinating and matching services to client needs could be improved by better diagnostic evaluation, taking into account the major differences of substance use disorders combined with internalizing, 
externalizing or psychotic disorders. The evidence suggests that among patients being treated for co-occurring mental and substance-use-related disorders, outcomes are improved when otherwise separate drug and psychiatric treatments are offered in combination within an integrated treatment plan that addresses both substance abuse and other psychiatric problems simultaneously.

\section{Other systems innovations}

Countries vary in the nature and extent of existing services. In order to build an optimal system of services, planning and quality improvement need to occur on a periodic basis. Three ways to do this are service mapping, needs assessment and needs-based planning.

Service mapping involves the description of system structures and qualities. WHO has designed a procedure for assessing, monitoring and evaluating treatment systems for substance use disorders in relation to population needs (4). The WHO-Substance Abuse Instrument for Mapping Services (SAIMS) identifies gaps in service delivery and specifies areas for system improvement.

In order to identify unmet treatment needs, some methods involve primary data collection and others rely on secondary analysis of existing data sources. Although there are no international standards for assessing unmet need, the SAIMS permits incremental planning that directs resources at the most important and manageable treatment needs in a population. The simplest procedure is to use population surveys to estimate the number of people in need of treatment. For example, the rates of dependence and harmful use can translate into the potential demand for specialized services (residential and outpatient) as well as early intervention services in other health care settings. The need for substance abuse services in the general population can also be estimated through the use of both health statistics and social indicators, such as substancerelated mortality and morbidity, social problem statistics, and expert opinion on treatment needs.

For service systems that are already well resourced, it may be more fruitful to conduct needs-based planning. This approach (33) requires the development of a model of the service system and uses population prevalence data to estimate the types of treatment services to be received by subgroups in the population; potentially including persons with various combinations of co-occurring disorders.

Another system innovation is workforce development to increase the number of trained professionals who can provide high-quality services. Although primary healthcare professionals can provide some types of care, substance abuse and mental health professionals, particularly psychiatrists, nurses, social workers and trained counsellors, are needed to manage those patients who are referred for specialized care and to deliver training, support and supervision to nonspecialists. Effective treatment policy requires planning for the preparation of this workforce, which should be integrated into their primary training rather than left to continuing education efforts afterwards.

In addition to the recruitment of trained professionals to manage the treatment of persons with severe dependence and its medical and psychiatric complications, there is a major role for nongovernmental organizations (NGOs) and self-help groups (34), particularly in relation to rehabilitation. Civil society can play a key role in the self-help movement, especially Narcotics Anonymous and Cocaine Anonymous. In many low- and middleincome countries, traditional healers are involved in treating substance use disorders (2). In the Eastern Mediterranean Region, The Turkish Green Crescent Society has an extensive network of programmes in Turkey, Palestine and Lebanon. In addition to treatment, it focuses on the protection of young people from tobacco, alcohol, drugs, gambling and technology addictions.

\section{Conclusions}

A high-level review by the Commission on Narcotic Drugs (35) reaffirmed that drug dependence is a health problem that requires further strengthening of public health system responses to drug-related problems. Consideration of system issues begins with the need to organize services to fit the needs of countries and communities. Prevalence of drug use in some Eastern Mediterranean Region countries is higher than the global average. High prevalence rates of drug use and its health and social consequences, particularly in countries like Afghanistan, Islamic Republic of Iran, and Pakistan, are also determined by the unique position of the region having countries with the largest production of opium in the world and straddling the major opioid trafficking routes. Other problems come with the high rates of alcohol and other substance abuse in guest worker communities in the Gulf States.

A model framework to guide the formulation of national drug treatment policy includes a series of logical steps designed to identify the basic needs of a country, bring the right stakeholders to the policy-making table, evaluate the evidence supporting effective strategies, and implement performance measurements to evaluate progress and provide feedback. Implementation of changes at the systems level will likely come in different forms depending on the existing services in a particular country as well as current trends in substance abuse within the general population. There are now a large number of evidenceinformed treatment interventions that are ready for implementation in systems of care in both low- and high-income countries. These interventions, along with innovations in the organization of 
services, can directly address the system quality issues discussed above, such as access, equity and coordination. Nevertheless, there are many obstacles to implementing changes across current treatment systems at the local, regional and national levels. While identification of evidence-based practices is a first step, attempts to implement major changes with therapist manuals and one-time workshops is unlikely to result in major changes. Rather, participatory planning, individual performance feedback, and specific incentives for implementation (e.g., money for training, pay raises and promotions) are needed to encourage systems to adopt new approaches $(8)$.

Beyond the implementation of evidence-based practices at the level of service providers and treatment programmes, changes in treatment policies that operate at the level of treatment systems are the most effective way to create an optimal configuration of treatment services. Coordination between the criminal justice system, mental health services, primary health care and the treatment system can reduce drug use, improve health, prevent crime and decrease recidivism. To the extent that treatment services organized within a system of early intervention, formal treatment and mutual-help organizations are based on effective strategies, they have the potential to have an impact at the population level in a variety of areas targeted by drug policy.

Given the diversity of system models and system development levels, each country needs to develop services that meet its own particular needs and resources. There is not a single system model that applies to all countries and development levels. Information from high-resourced countries may not easily transfer to low-resourced countries. Greater cooperation and networking among service system planners at similar development levels should be encouraged, in order to share information about system elements that may have higher priority (e.g., mutual help, primary care and professional training), especially in low- and middle-income countries.

Planned innovation should be a high priority in the improvement of service systems. Systems concepts and data should be used to introduce innovations into the service systems to improve accessibility, equity, efficiency, effectiveness and quality. The sociocultural context of disadvantaged communities, guest workers, and indigenous populations should be a major priority in the planning and development of service systems.

Activities to strengthen treatment service systems should include the following elements:

- regional collaboration to oversee treatment mapping exercises and service planning activities;

- provision of feedback to national health authorities regarding the current status of national treatment systems based on the results of population needs assessment and treat- ment mapping exercises to improve the availability and effectiveness of services;

- networking among treatment programme administrators, public health authorities, academics and other stakeholders to share information, experience and best practices;

- workforce development activities training and continuing education;

- quality assessment and quality improvement activities; and

- applied research that informs the further development of service systems.

No matter how efficacious a treatment may be, it will produce little benefit to individuals and society if it is not available, accessible and provided in a way that encourages help-seeking and retention in care. This presents opportunities for improving the population impact of treatment and prevention by means of better coordination with mental health, primary care and criminal justice interventions.

\section{Acknowledgements}

The author thanks Katherine Robaina and Keith Humphreys for their helpful comments. The conceptual model on which this paper is based was derived from earlier work in the book, "Drug Policy and the Public Good", which is cited in the figure and the references.

Funding: None.

Competing interests: None declared.

\section{References}

1. Al Marri TS, Oei TP. Alcohol and substance use in the Arabian Gulf region: a review. Int J Psychol. 2009 Jun;44(3):222-33. PMID:22029498

2. ATLAS on Substance Use: resources for the prevention and treatment of substance use disorders. Geneva: World Health Organization; 2010 (http://www.who.int/substance_abuse/ activities/atlas/en/, accessed 14 March 2017).

3. Babor T, Caulkins J, Edwards G, Fischer B, Foxcroft D, Humphreys K, et al. Drug policy and the public good. Oxford: Oxford University Press; 2010.

4. Babor TF, Poznyak V. The World Health Organization substance abuse instrument for mapping services: rationale, structure and functions. Nord Stud Alcohol Drugs. 2010;27(6):703-11 (http:// www.nordicwelfare.org/PageFiles/4930/15_Babor.pdf).

5. Emmanuelli J, Desenclos J-C. Harm reduction interventions, behaviors and associated health outcomes in France, 19962003. Addiction. 2005 Nov;100:1690-700. PMID:16277629

6. Killias M, Aebi MF. The impact of heroin prescription on heroin markets in Switzerland. Crime Prev Stud. 2000;11:8399 (http://www.popcenter.org/library/crimeprevention/ volume_11/04-Killias.pdf).

7. Smart RG, Mann RE. The impact of programs for high-risk drinkers on population levels of alcohol problems. Addiction. 2000 Jan;95(1):37-51. PMID:10723824 
8. Morisano D, Babor TF, Robaina KA. Co-occurrence of substance use disorders with other psychiatric disorders: implications for treatment services. Nord Stud Alcohol Drugs. 2014 Feb;31(1):5-25 (https://www.degruyter.com/view/j/ nsad.2014.31.issue-1/nsad-2014-0002/nsad-2014-0002.xml).

9. Rush B. Tiered frameworks for planning substance use service delivery systems: origins and key principles. Nord Stud Alcohol Drugs. 2010;27(6):617-36 (http://www.nordicwelfare.org/ PageFiles/4930/08_Rush.pdf).

10. Babor TF, McRee BG, Kassebaum PA, Grimaldi PL, Ahmed K, Bray J. Screening, Brief Intervention, and Referral to Treatment (SBIRT): toward a public health approach to the management of substance abuse. Subst Abus. 2007;28(3):7-30. PMID:18077300

11. Humeniuk RE, Ali RL, Babor T, Souza-Formigoni MLO, de Lacerda RB, Ling W, et al. A randomized controlled trial of a brief intervention for illicit drugs linked to the Alcohol, Smoking and Substance Involvement Screening Test (ASSIST) in clients recruited from primary health-care settings in four countries. Addiction. 2012 May;107(5):957-66. PMID:22126102

12. Jensen CD, Cushing CC, Aylward BS, Craig JT, Sorell DM, Steele RG. Effectiveness of motivational interviewing interventions for adolescent substance use behavior change: a metaanalytic review. J Consult Clin Psychol. 2011 Aug;79(4):433-40. PMID:21728400

13. Rapp RC, Otto AL, Lane DT, Redko C, McGatha S, Carlson RG. Improving linkage with substance abuse treatment using brief case management and motivational interviewing. Drug Alcohol Depend. 2008 Apr 1;94(1-3):172-82. PMID:18242883

14. Kleiman M. Controlling drug use and crime among druginvolved offenders: Testing, sanctions, and treatment. In: Heymann PH, Brownsberger WN, editors. Drug Addiction and Drug Policy. The struggle to control dependence. Cambridge, MA: Harvard University Press; 2001.

15. DuPont RL, McLellan AT, Carr G, Gendel M, Skipper GE. How are addicted physicians treated? A national survey of physician health programs. J Subst Abuse Treat. 2009 Jul;37(1):1-7. PMID:19482236

16. Drug Treatment Court Program for the Americas. Volume 1. Inter-American Drug Abuse Control Commission/Organization of American States; 2013 (http://www.cicad.oas.org/fortalecimiento_institucional/dtca/Resources/Newsletters/Newsletter\%202013\%20Vol\%201.pdf, accessed 14 March 2017).

17. Gottfredson DC, Najaka SS, Kearly B. Effectiveness of drug treatment courts: evidence from a randomized trial. Criminol Public Policy. 2003;2(2):171-96 (https://ccjs.umd.edu/sites/ ccjs.umd.edu/files/pubs/gottfredson2003.pdf).

18. Wilson DB, Mitchell O, MacKenzie DL. A systematic review of drug court effects on recidivism. J Exp Criminol. 2006;2(4):45987.

19. Mitchell O, Wilson DB, Eggers A, MacKenzie DL. Assessing the effectiveness of drug courts on recidivism: a meta-analytic review of traditional and non-traditional drug courts. J Crim Justice. 2012 Jan-Feb;40(1):60-71.

20. Rossman S, Rempel M, Roman JK, Zweig JM, Lindquist CH, Green $M$ et al. The Multi-site adult drug court evaluation: the impact of drug courts. Volume 4. Washington: Urban Institute Justice Policy Center; 2011 (https://www.ncjrs.gov/pdffiles1/ nij/grants/237112.pdf, accessed 14 March 2017).

21. Pearson FS, Lipton DS. A meta-analytic review of the effectiveness of corrections-based treatments for drug abuse. Prison J. 1999;79:384-410

22. Mitchell O, Wilson DB, MacKenzie DL. Does incarcerationbased drug treatment reduce recidivism? A meta-analytic synthesis of the research. J Exp Criminol. 2007 Dec;3(4):353-75.

23. Hedrich D, Alves P, Farrell M, Stover H, Moller L, Mayet S. The effectiveness of opioid maintenance treatment in prison settings: a systematic review. Addiction. 2012 Mar;107:501-17. PMID:21955033

24. Seddon T. Coerced drug treatment in the criminal justice system: conceptual, ethical and criminological issues. Criminol Crim Justice. 2007;7(3):269-86.

25. Stevens A. The ethics and effectiveness of coerced treatment of people who use drugs. Hum Rights Drugs. 2012;2(1):7-15.

26. Caplan AL. Ethical issues surrounding forced, mandated or coerced treatment. J Subst Abuse Treat. 2006 Sep;31(2):117-20. PMID:16919736

27. UNAIDS. Joint statement. Compulsory drug detention and rehabilitation centres; 2012 (http://www.unaids.org/sites/ default/files/sub_landing/files/JC2310_Joint\%20Statement6March12FINAL_en.pdf, accessed 14 March 2017).

28. United Nations Office on Drugs and Crime, World Health Organization. Principles of drug dependence treatment; 2008 (http://www.unodc.org/documents/drug-treatment/ UNODC-WHO-Principles-of-Drug-Dependence-TreatmentMarch08.pdf, accessed 14 March 2017).

29. Buckley PF. Prevalence and consequences of the dual diagnosis of substance abuse and severe mental illness. J Clin Psychiatry. 2006;67 Suppl 7:5-9. PMID:16961418

30. Cleary M, Hunt G, Matheson S, Siegfried N, Walter G. Psychosocial interventions for people with both severe mental illness and substance misuse. Cochrane Database Syst Rev. 2008;1.

31. Minkoff K. An integrated model for the management of CO-Occurring psychiatric and substance disorders in managed-care systems. Dis Manag Health Outcomes. 2000 Nov;8(5):251-7.

32. Miller WR, Carroll K. Rethinking substance abuse: what the science shows, and what we should do about it. New York: Guilford Press; 2006.

33. Rush B. (2014). Evaluating the complex: alternative models and measures for evaluating collaboration among substance use services with mental health, primary care and other services and sectors. Center for Addiction and Mental Health. Unpublished report.

34. Medina-Mora ME. Can science help close the treatment gap? Addiction. 2010 Jan;105(1):15-6. PMID:20078455

35. Political declaration and plan of action on international cooperation towards an integrated and balanced strategy to counter the world drug problem. Vienna: United Nations Office on Drugs and Crime; 2009 (https://www.unodc.org/ documents/ungass2016/V0984963-English.pdf, accessed 14 March 2017). 